\title{
The effect of eccentricity and the adapting level on the café wall illusion
}

\author{
TATSUTO TAKEUCHI \\ NTT Communication Science Laboratories, Atsugi, Japan
}

\begin{abstract}
The café wall pattern is composed of rows of alternating light and dark tiles, and alternate rows are shifted by one fourth of a cycle. The rows of tiles are separated by narrow horizontal mortar lines whose luminance is between those of the dark and the light tiles. Although the mortar lines are physically parallel, they are perceived to be tilted, which is known as the café wall illusion. In this study, an energy-based model for encoding orientation is implemented in order to estimate the strength of the café wall illusion, and it is shown that the estimated orientation depends on the spatial frequency to which each orientation-encoding unit is tuned. The estimation of mortar line orientation from an orientationencoding unit tuned to a lower spatial frequency was greater than that from a unit tuned to a higher spatial frequency. It is assumed that the perceived mortar line orientation is the result of an integration of responses from the orientation-encoding units tuned to various spatial frequencies. This leads to the prediction that under viewing conditions in which responses from orientation-encoding units tuned to a higher spatial frequency are presumably weakened, the strength of the café wall illusion increases. In agreement with this prediction, it is shown that the café wall illusion is stronger when the café wall image is presented at the periphery or is observed under low luminance levels. On the other hand, the weighted averaging of the estimated mortar orientations across spatial frequencies overestimates the perceived orientation of the mortar lines. This suggests that the final percept of the café wall illusion could be determined by some kind of nonlinear interaction, such as an inhibitory interaction, between orientation-encoding units.
\end{abstract}

In geometrical illusions, the perceived orientation of contours often deviates from what it really is (e.g., Gregory, 1968; Rock, 1986). The café wall illusion is a well-known geometrical illusion. The café wall pattern (Figure 1A) is composed of rows of alternating light and dark tiles, and the rows are shifted by one fourth of a cycle. The rows of tiles are separated by narrow horizontal mortar lines whose luminance is between those of the dark and the light tiles. Although the mortar lines are physically parallel, they are perceived to be tilted (Gregory, 1972; Gregory \& Heard, 1979). The café wall pattern is a variation of the Münsterberg figure, in which the mortar lines have the same luminance as the dark tiles (Fraser, 1908; Münsterberg, 1897). When the mortar luminance is darker than the dark tiles (Figure 1B) or lighter than the light tiles, the strength of the illusion is largely reduced (Gregory \& Heard, 1979).

A prominent characteristic of the primary visual cortex is that most neurons have selectivity for patterns of a specific orientation and spatial frequency, and the particular opti-

The author thanks Allison B. Sekuler and two anonymous reviewers for their helpful comments on the manuscript and Naohiro Aihara for his excellent technical assistance. Correspondence concerning this article should be addressed to T. Takeuchi, NTT Communication Science Laboratories, Nippon Telegraph and Telephone Corporation, MorionosatoWakamiya 3-1, Atsugi, Kanagawa 243-0198, Japan (e-mail: tatsuto@ apollo3.brl.ntt.co.jp). mum orientation and spatial frequency varies from cell to cell (e.g., R. L. De Valois \& K. K. De Valois, 1988; Hubel \& Wiesel, 1962). There is also psychophysical evidence that there is a specialized mechanism for encoding orientation and spatial frequency (e.g., Blakemore \& Campbell, 1969; Campbell \& Kulikowski, 1966; R. L. De Valois \& K. K. De Valois, 1988; Phillips \& Wilson, 1984). Since the café wall illusion is an orientation-specific phenomenon, it seems reasonable to explain it upon the basis of an orientationencoding mechanism in the visual system. In fact, several studies have suggested that the café wall illusion is induced by outputs from a mechanism that selectively responds to specific orientations in the image (Haig, 1989; Lulich \& Stevens, 1989; Morgan \& Moulden, 1986).

When the café wall figure is convolved with a difference of Gaussians (DoG) operator, a twisted cord (Fraser, 1908) of alternating light and dark diagonal bands appears (Earle \& Maskell, 1993; Lulich \& Stevens, 1989; Morgan \& Moulden, 1986). This twisted cord has been thought to be the basis of the café wall illusion, since locally tilted segments of twisted cords elicit a global impression of orientation (Morgan \& Moulden, 1986; Tyler \& Nakayama, 1984). Lulich and Stevens suggested that these locally tilted segments are detected by a bank of spatially oriented filters in the striate cortex and that this induces the impression of orientation on the physically parallel mortar lines in the café wall figure (see also Morgan \& Moulden, 1986). 
(A)

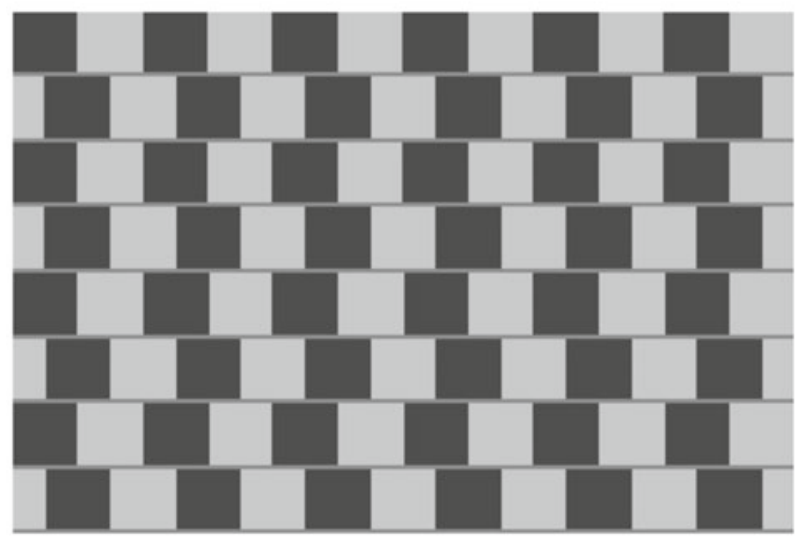

(B)

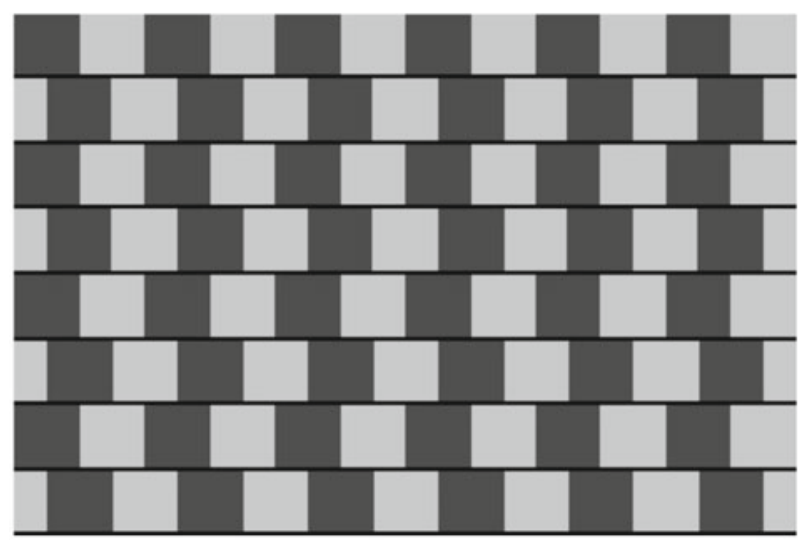

Figure 1. (A) The café wall pattern. It is composed of rows of alternating light and dark tiles, and the rows are shifted by one fourth of a cycle. The rows of tiles are separated by narrow horizontal mortar lines with a luminance intermediate between those of the dark and the light tiles. Although the mortar lines are physically parallel, they are perceived to be tilted from horizontal, which is known as the café wall illusion. (B) When the mortar luminance is darker than the dark tiles, the strength of the café wall illusion is greatly reduced.

As was described above, orientation-encoding units have their own preferred spatial frequencies. However, the relationship between the selectivity to spatial frequencies and the café wall illusion has not been considered in previous studies. Morgan and Casco (1990) examined the role of spatial filtering on the Zöllner and Judd class of geometrical illusion and found that the smaller DoG filters induced a smaller error in the estimation of orientation or length (thus, a smaller strength of illusion) than those found in the psychophysical experiments. Their finding suggests that the magnitude of the geometrical illusions depends on the scale of the spatial filters that detect orientation or line length. The purpose of the present study is to examine how the strength of the café wall illusion depends on the spatial frequencies characteristic of orientation-encoding units.
In the first part of this study, an implementation of the currently prevailing energy-based spatial-frequencyselective orientation-encoding model, which is considered to be physiologically and psychophysically plausible (Heeger, 1992; Malik \& Perona, 1990; Morrone \& Burr, 1988) will be described. It is shown that the estimated orientation of the mortar line (the strength of the café wall illusion) depends on the spatial frequencies to which each orientation-encoding unit is tuned. In general, the estimated illusion is larger when an orientation-encoding unit is tuned to a lower spatial frequency and smaller when it is tuned to a higher one. This result points to possible effects of two psychophysical characteristics of the café wall illusion that have not been examined before. One is the effect of eccentricity (retinal location), and the other is the effect of the average luminance level (adaptation level) on the café wall illusion, since contributions from orientation-encoding units tuned to a higher spatial frequency decrease as eccentricity increases or average luminance decreases. In the second part of this article, psychophysical experiments will be described in which those two effects on the perception of the café wall image were examined. The eccentricity and the average luminance levels were systematically varied, and it was found that the illusion was greater when the café wall image was presented at the periphery or was observed under low luminance levels. These psychophysical characteristics can be explained by assuming that the final percept of the café wall illusion is determined by an integration of signals from orientation-encoding units having different spatial frequency selectivity.

\section{Outline of the Orientation Energy Model}

In the orientation energy model implemented here, the outputs from the four spatially oriented linear filters that have a quadrature relationship (a spatial phase difference between two adjacent filters of $90^{\circ}$ ) are squared and summed to give the square of local energy. Energy-based models can predict many of the physiological and psychophysical responses to various image features, including orientation, motion, texture, and stereoscopic depth (e.g., Adelson \& Bergen, 1985; Anzai, Ohzawa, \& Freeman, 1999; Bergen \& Landy, 1991; Carandini, Heeger, \& Movshon, 1999; Emerson, Bergen, \& Adelson, 1992; Heeger, 1992; Malik \& Perona, 1990; Morrone \& Burr, 1988; Ohzawa, DeAngelis, \& Freeman, 1990; Pollen \& Ronner, 1983; Watson \& Ahumada, 1985). The quadrature phase relationship between the four linear filters used in the model is adopted from an energy model of the complex cell in V1 (e.g., DeAngelis \& Anzai, 2004; Heeger, 1992). In the Discussion section, an additional simulation will be described in which a single filter, not four, was applied to the café wall image.

Two of the spatial impulse response functions are the two-dimensional even-symmetric or odd-symmetric Gabor functions that constitute a quadrature pair. The phases of the other two filters are the sign-inverted versions of each Gabor filter. The Gabor function, a one- 
dimensional cosine wave tapered by a two-dimensional Gaussian, has been shown to be a good approximation of the receptive field of a simple cell in the striate cortex (Daugman, 1985; R. L. De Valois \& K. K. De Valois, 1988; Field \& Tolhurst, 1986). The two-dimensional Gabor filter is defined as

$$
\begin{aligned}
G(x, y) & =\exp \left(-\frac{x^{\prime 2}+y^{\prime 2}}{2 \sigma^{2}}\right) \cos \left(2 \pi \frac{x^{\prime}}{\lambda}+\varphi^{\prime}\right), \\
x^{\prime} & =x \cos \theta-y \sin \theta, \\
y^{\prime} & =x \sin \theta+y \cos \theta,
\end{aligned}
$$

where $(x, y)$ specifies the spatial position and $x^{\prime}$ and $y^{\prime}$ are coordinates rotated by angle $\theta$. The standard deviation of the Gaussian function $(\sigma)$ and the wavelength $(\lambda)$ determine the size of the filter and the filter's preferred spatial frequency $(1 / \lambda)$, respectively. The phase $\varphi$ was varied from 0 to $3 \pi / 2$ in $\pi / 2$ steps; thus, adjacent filters are in quadrature relationship. The Gabor filter was represented on a field of $512 \times 512$ pixels, the same size as the input café wall.

Thirty-six units were prepared that were tuned for orientation $(\theta)$ in $5^{\circ}$ increments, in order to cover the whole orientation range. As was mentioned above, each orientationselective unit is composed of four linear filters with different phases, to constitute an energy-detecting mechanism. Several examples of $x y$ images of the Gabor filter are shown in Figures 2 and 3. The half-amplitude orientation bandwidth of each filter, computed at its Fourier-transformed response, was $30^{\circ}$, which roughly corresponds to the psychophysical measurement by Phillips and Wilson (1984).

Center spatial frequencies $(1 / \lambda)$ of the filters were set from 1.0 to $16.0 \mathrm{c} / \mathrm{deg}$, on the assumption that the input café wall image shown in Figure 2 has the same spatial scale as that used in the psychophysical experiments

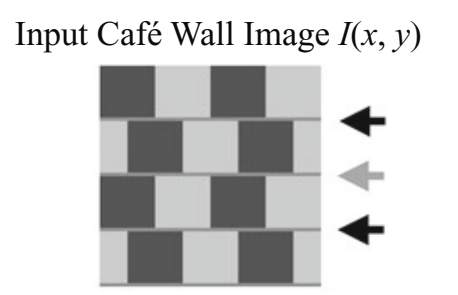

Perceived Orientation of the Mortar Lines

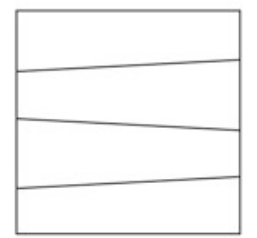

Gabor Filter $G(x, y)$ Tuned to $90^{\circ}$

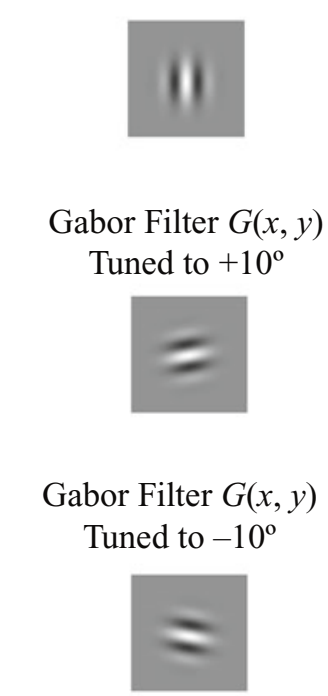

Orientation Energy $E(x, y)$
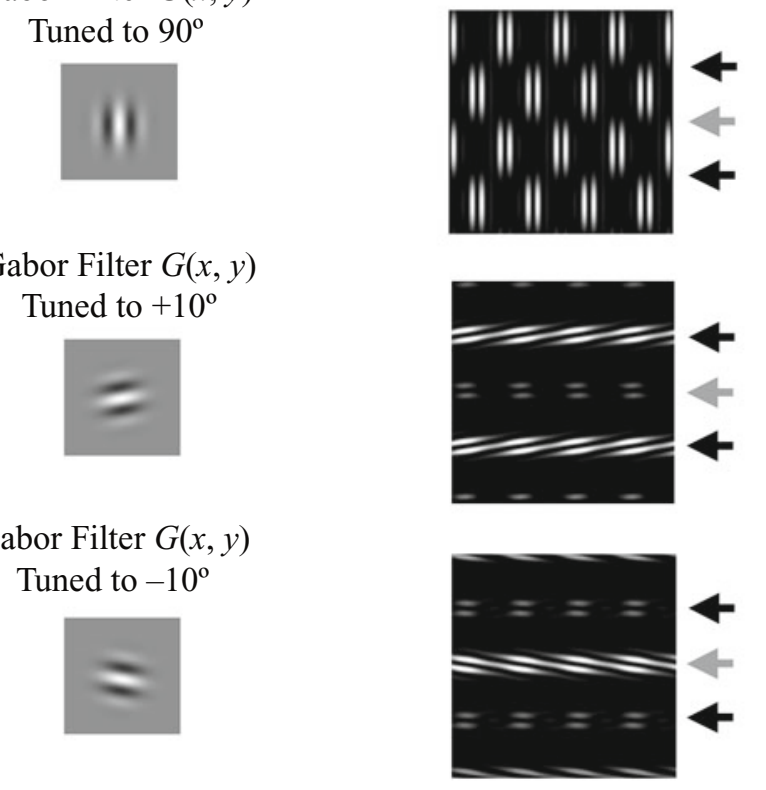

Figure 2. On top are the input café wall image $[I(x, y)]$ and a schematic description of the perceived direction of orientation. The arrows show the position of the three mortar lines. The mortar lines have a luminance intermediate between those of the light and the dark tiles. Below the café wall image are schematic descriptions of the two-dimensional Gabor filters $[G(x, y)]$ and illustrations of the $x y$ plots of the orientation energy $[E(x, y)]$ derived from the model. Black corresponds to a zero response, and white to the normalized maximum response in the output images. The three arrows next to each output image show the corresponding positions of the mortar lines of the input café wall image. 
described later $\left(4^{\circ} \times 4^{\circ}\right)$. The standard deviation $(\sigma)$ in Equation 1 was obtained with the following equation (Kruizinga \& Petkov, 1999; Petkov \& Kruizinga, 1997); the half-amplitude bandwidth $B$ of the spatial frequency was set to 1.2 octaves, which roughly corresponds to the average striate cell's tuning width (R. L. De Valois, Albrecht, \& Thorell, 1982) and the psychophysical data (Wilson, McFarlane, \& Phillips, 1983):

$$
\sigma=\frac{\lambda}{\pi} \sqrt{\frac{\ln 2}{2}} \cdot \frac{2^{B}+1}{2^{B}-1} .
$$

To extract the specific orientation energy involved in the input image $I(x, y)$, the four spatial filters are convolved with the input image (a café wall image), and their outputs are squared and summed at each point of the input image. If orientation energy exists at a particular spatial position of the input image, a response appears at that point. Thus, the response $E(x, y)$ from a Gabor filter $G(x, y)$ at each point in the input image is defined as follows:

$$
\begin{aligned}
E(x, y)= & {\left[I(x, y) * G^{0}(x, y)\right]^{2}+\left[I(x, y) * G^{\pi / 2}(x, y)\right]^{2} } \\
& +\left[I(x, y) * G^{\pi}(x, y)\right]^{2}+\left[I(x, y) * G^{3 \pi / 2}(x, y)\right]^{2} .
\end{aligned}
$$

The superscript on $G(x, y)$ specifies the phase $(\varphi)$ of the Gabor filter. $E(x, y)$ was calculated in the frequency domain.

In this simulation, different estimated orientations of a mortar line (strength of the café wall illusion) are obtained across the spatial frequencies to which the orientationencoding units are tuned. In the next section, how those estimated mortar line orientations depend on the spatial frequency to which each orientation-encoding unit is tuned will be described. Since a perceived mortar line orientation in the café wall image is unique, an integration process should be incorporated that combines responses from orientation-encoding units tuned to various spatial frequencies. In the Discussion subsection of the Experiment section and in the General Discussion section, an attempt to examine a weighted averaging of the estimated orientation across spatial frequencies as a possible integration process and to match the estimated value to the psychophysical data will be described.

\section{Estimation of Perceived Orientation in the Café Wall Figure}

To estimate the perceived orientation of the mortar lines, the orientation energy $E(x, y)$ of the model described above (Equation 3) was calculated. Figure 2 shows the input image of the café wall figure $[I(x, y)]$, images of the oriented Gabor filters $[G(x, y)]$, and images of the output (orientation energy) from the model $[E(x, y)]$. The stimulus size was $512 \times 512$ pixels, with 256 gray levels.

The arrows in the café wall figure show the position of three mortar lines. The mortar lines have a luminance intermediate between that of the light and the dark tiles, which induces a strong café wall illusion (Gregory \& Heard, 1979). The orientation of each mortar line is perceived to deviate from horizontal. The first and the third mortar lines, whose position is shown by black arrows, are perceived as tilting from lower left to upper right. The second mortar line, whose position is shown by the gray arrow, is perceived as tilting from upper left to lower right. A schematic description of the perceived orientation in the illusion is shown in the first row (for clarity, the amount of tilt is exaggerated).

Two-dimensional Gabor filters, $G(x, y)$, are shown schematically in their preferred orientations of $90^{\circ}$ (vertical), $+10^{\circ}$, and $-10^{\circ}$. The plus value indicates that the horizontal grating rotates counterclockwise, and the negative value indicates that the horizontal grating rotates clockwise from horizontal. If it is assumed that the café wall image in Figure 2 has the same spatial scale as that used in the psychophysical experiments, the spatial frequency components of each image can be represented in cycles per degree. Then, the center spatial frequency of each Gabor filter corresponds to $3.0 \mathrm{c} / \mathrm{deg}$.

The output images $E(x, y)$ are $x y$ plots derived from the units with preferred orientations of $90^{\circ},+10^{\circ}$, or $-10^{\circ}$. In these images, light shading indicates a stronger orientation energy response, and dark shading indicates a weaker one. Black corresponds to a zero response, and white to the normalized maximum response. The three arrows show the corresponding position of the mortar lines in the input café wall image.

When the filter orientation was vertical $\left(90^{\circ}\right)$, a strong response (light-shaded region in the output image) was seen mainly at both sides of the vertical edges composed of the light and dark tiles. It should be noted that strong responses were observed equally at two different types of edges: one formed by a light tile on the left and a dark tile on the right, and the other formed in the opposite way. The orientation energy appeared in a phase-insensitive manner, because of the energy calculation. The result shows that the orientation mechanism selective to vertical strongly responded to the vertical edges, not to the horizontal lines (the mortar lines).

When the filter orientation deviated $\pm 10^{\circ}$ from horizontal, the orientation energy response localized around the mortar lines. When the filter was tilted counterclockwise $\left(+10^{\circ}\right)$, a strong response was observed at the first and third mortar lines. However, when the filter was tilted clockwise $\left(-10^{\circ}\right)$, a strong response was observed at the middle mortar line. As is shown at the top of Figure 2, the first and third mortar lines are perceived to be tilted counterclockwise from horizontal, and the second mortar line is perceived to be tilted clockwise. Therefore, at the horizontal mortar lines, the energy of orientation deviates from horizontal, and the direction of the deviation corresponds to perception of the café wall illusion.

The unit tuned to $+10^{\circ}$ also responded to the middle mortar line, and the unit tuned to $-10^{\circ}$ was activated at the position of the first and third mortar lines, although the amount of the response was small. This is because the bandwidth of each orientation-selective unit computed at their Fourier-transformed response was $30^{\circ}$. 
Figure 3 shows the results of simulation using different orientation-encoding units whose preferred spatial frequency was $6.0 \mathrm{c} / \mathrm{deg}$ and preferred orientations were $+5^{\circ},-5^{\circ}$, and $0^{\circ}$. An additional input image whose mortar lines were black was also used. As is shown in the orientation energy $E(x, y)$ for the two input café wall images, when the mortar had an average luminance, orientation energy was conspicuous at the first and third mortar lines when the unit tuned to $+5^{\circ}$ was used. However, strong energy extracted by the unit tuned to $-5^{\circ}$ appeared only at the middle mortar line. As in Figure 2, the asymmetrical response of the orientation-encoding mechanism qualitatively corresponds to the perception of the orientation of the mortar lines. Outputs from the unit tuned to $0^{\circ}$ (horizontal) indicate that horizontal orientation energy also exists at the three mortar lines. When the mortar lines were black, all three orientation-selective units elicited responses at the three mortar lines, and a large asymmetrical response distribution, as shown between the units tuned to $+5^{\circ}$ and $-5^{\circ}$, was no longer observed. ${ }^{1}$

Next, the way in which the perceived orientation of the mortar lines is uniquely decided from the outputs of units tuned to various orientations and spatial frequencies will be described. To calculate the net orientation energy from each orientation-selective unit, the local energy $E(x, y)$ distributed at a mortar line of the input café wall image was summed to induce a total energy $T E(\theta)$ at a mortar line. The assumption underlying this operation is that there is a mechanism that integrates the outputs from spatially local units to induce a global percept of the orientation of the mortar lines. The calculated $T E(\theta)$ was normalized by dividing the maximum $T E(\theta)$ found in the whole orientation range $\left(\theta=0^{\circ}-180^{\circ}\right)$ to unity at each spatial frequency.
Figure 4 shows how $\operatorname{TE}(\theta)$ varies as a function of the orientation of a Gabor filter. The input was a café wall image in which the normalized luminances of the dark and light tiles were 0.2 and 0.8 and the luminance of the mortar line was 0.5 (average; Figure 4A) or 0.1 (darker than the dark tiles; Figure 4B). Figures $4 \mathrm{C}$ and $4 \mathrm{D}$ show the normalized $\operatorname{TE}(\theta)$ at the mortar line shown by the arrow in Figures 4A or 4B as a function of the preferred orientation $(\theta)$ of an orientation-encoding unit, whose preferred spatial frequency was $3.0 \mathrm{c} / \mathrm{deg}$ (Figure $4 \mathrm{C}$ ) or $6.0 \mathrm{c} / \mathrm{deg}$ (Figure 4D).

When the mortar luminance was 0.1 (black squares), the maximum orientation energy was obtained when the preferred orientation of the unit was $0^{\circ}$ (horizontal), as is shown in Figures 4C and 4D. The orientation energy decreased as the preferred orientation deviated from $0^{\circ}$. However, when the mortar luminance was the average of that of the dark and the light tiles (0.5; gray squares), the maximum energy was obtained from the unit whose preferred orientation was $+10^{\circ}$ (Figure $4 \mathrm{C}$ ) or $+5^{\circ}$ (Figure 4D). Energy decreased as the preferred orientation deviated from $+10^{\circ}$ or $+5^{\circ}$. Therefore, even though the gray mortar line is physically horizontal, the orientation energy is stronger at $+10^{\circ}$ or $+5^{\circ}$ than at $0^{\circ}$ (horizontal).

To quantitatively estimate the perceived orientation of mortar lines, responses from neighboring orientationselective units were interpolated with a Gaussian. By employing an interpolation, the accuracy of the estimation is expected to become better than the spacing between neighboring preferred orientations $\left(5^{\circ}\right.$; Wilson, Ferrera, \& Yo, 1992). The smooth curves in Figures 4C and 4D show the results of the interpolation for estimating the perceived orientation of the mortar lines. When the mortar

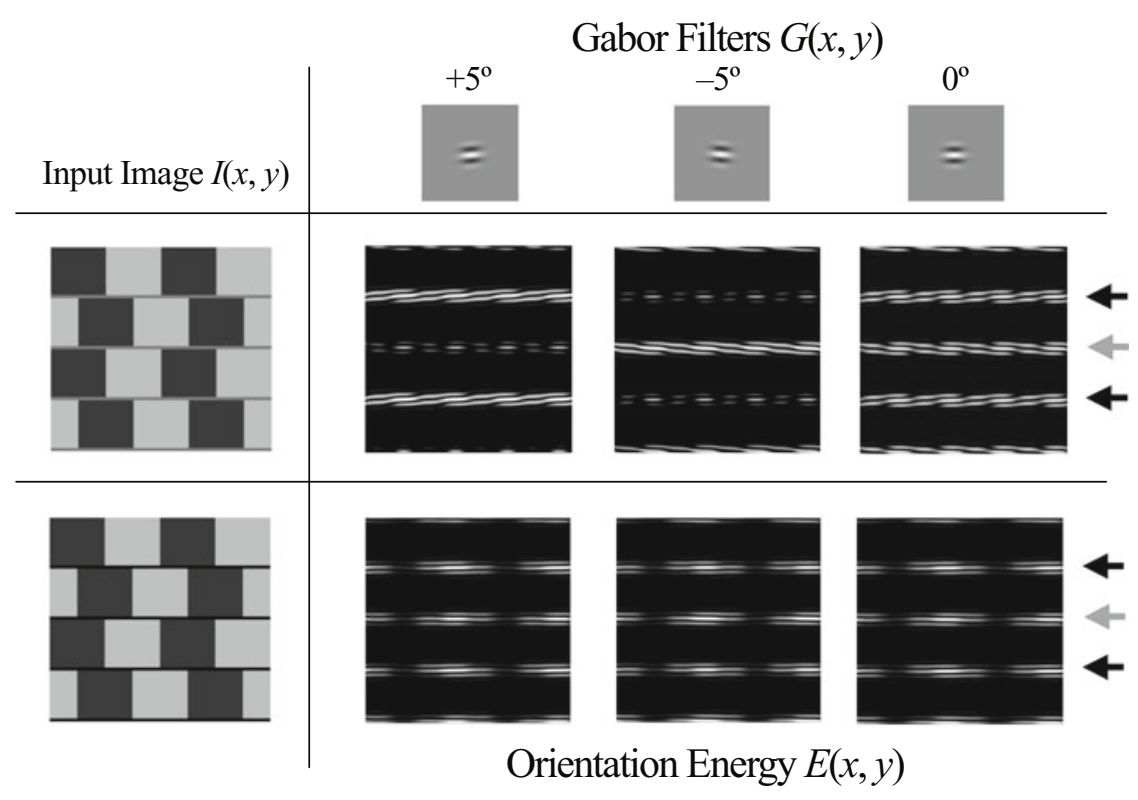

Figure 3. The input café wall images $[I(x, y)]$ with gray and black mortar lines, schematic descriptions of the two-dimensional Gabor filters $[G(x, y)]$, and illustrations of the $x y$ plots of the orientation energy $[E(x, y)]$ derived from the model.t 
(A)

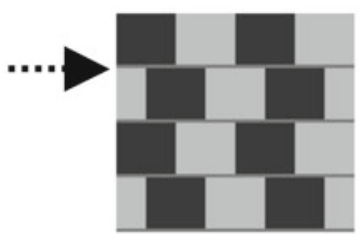

(B)

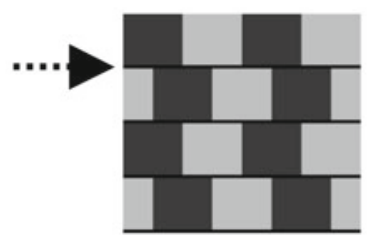

(C) Preferred spatial frequency $=3.0 \mathrm{c} / \mathrm{deg}$

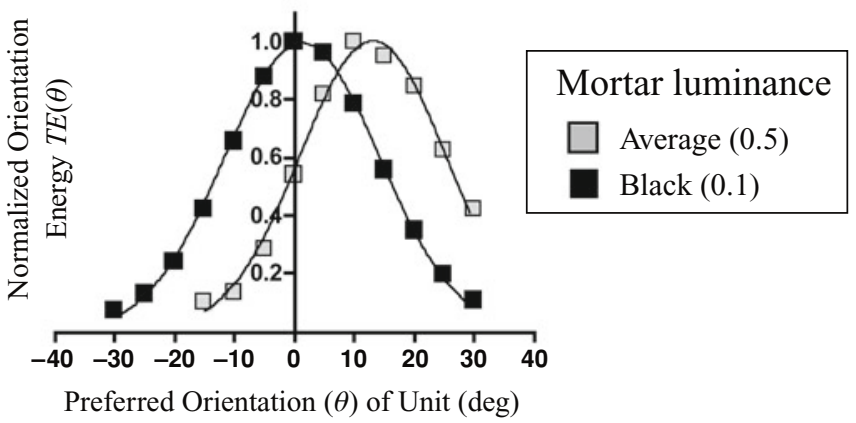

(D) Preferred spatial frequency $=6.0 \mathrm{c} / \mathrm{deg}$

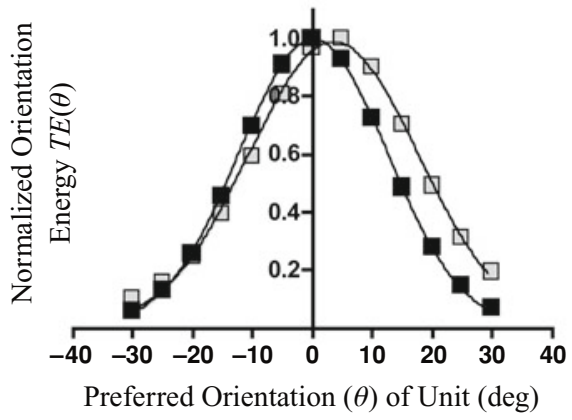

Figure 4. (A) Input café wall image with gray mortar lines (normalized luminance, 0.5). (B) Input café wall image with dark mortar lines (normalized luminance, 0.1$)$. (C) Normalized orientation energy $T E(\theta)$ distributed at a mortar line (the positions of the mortar lines are indicated by dashed arrows in the input café wall images) as a function of a preferred orientation $(\theta)$ of an orientationencoding unit in degrees. Preferred spatial frequency of the orientation-encoding units is $3.0 \mathrm{c} / \mathrm{deg}$. Gray squares are for the average mortar luminance (0.5), and black squares are for the black mortar luminance $(0.1)$. The curves show the results of interpolation to estimate the perceived orientation of the mortar line. (D) Preferred spatial frequency of the orientation-encoding units is $6.0 \mathrm{c} / \mathrm{deg}$. Other conditions are the same as those in panel $C$.

line has the average luminance (0.5), the estimated orientation is $13.3^{\circ}$ in Figure $4 \mathrm{C}$ and $3.7^{\circ}$ in Figure 4D. For the dark mortar line $(0.1)$, the estimated orientation is $1.4^{\circ}$ in Figure $4 \mathrm{C}$ and $0.3^{\circ}$ in Figure 4D. The orientation energy model therefore predicts that a physically horizontal gray mortar line will be perceived to be tilted, and it will be perceived to be nearly horizontal when the luminance of the mortar line is 0.1 .

The same procedure was repeated for various mortar luminances with different orientation-encoding units tuned to various spatial frequencies, and the results are shown in Figure 5. In Figure 5A, the estimated perceived orientation of mortar lines for different preferred spatial frequencies of an orientation-encoding unit is plotted as a function of normalized mortar luminance. For each spatial frequency, the perceived orientation of the mortar line increased with increasing mortar line luminance until it reached the luminance of 0.5 , the average of the luminance of the light and dark tiles. This is qualitatively consistent with previous psychophysical studies that have shown the effect of mortar luminance on the strength of the café wall illusion (Gregory \& Heard, 1979; Morgan \& Moulden, 1986). Figure 5B, the replot of Figure 5A, represents the estimated orientation of mortar lines for differ- 


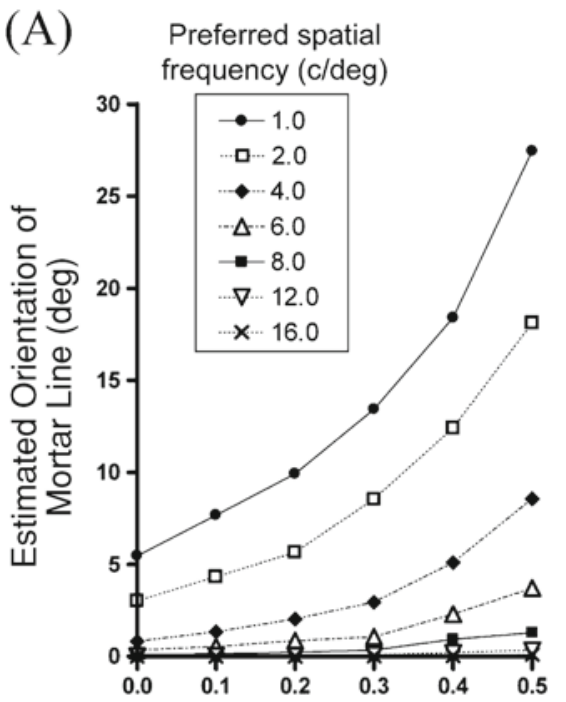

Normalized Mortar Luminance
(B)

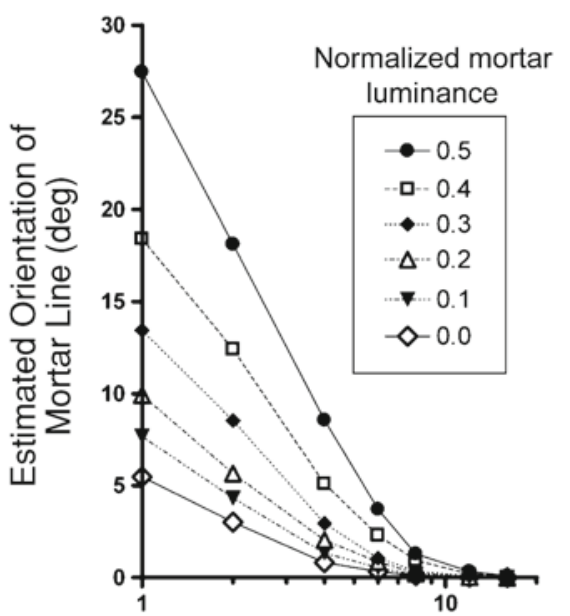

Preferred Spatial Frequency (c/deg)

Figure 5. (A) The estimated orientation of mortar lines (in degrees) is plotted as a function of normalized mortar luminance. Different symbols indicate a preferred spatial frequency of an orientationencoding unit, varied from 1.0 to $16.0 \mathrm{c} / \mathrm{deg}$. (B) The estimated orientation of mortar lines shown in panel $A$ is replotted as a function of preferred spatial frequency of an orientation-encoding unit (c/deg). Different symbols indicate a normalized mortar luminance of the input café wall image, varied from 0.0 (black) to 0.5 (average).

ent normalized mortar luminances as a function of spatial frequencies of an orientation-encoding unit. Figure 5B clearly shows that the estimated strength of the café wall illusion decreases as the preferred spatial frequency of the orientation-encoding unit increases.

What was found from this simulation is that the estimated orientation depends not only on the mortar luminance, but also on the preferred spatial frequency of orientation-encoding units. For example, when the orientation-encoding unit tuned to a spatial frequency of $1.0 \mathrm{c} / \mathrm{deg}$ was used, the estimated orientation was about $30^{\circ}$ when the mortar luminance was 0.5 , whereas it was less than $1^{\circ}$ when the unit tuned to $12.0 \mathrm{c} / \mathrm{deg}$ was used at the same mortar luminance.

\section{Discussion}

There is no guarantee that the interpolation applied in Figure 4 is similar to the neural operations of the human visual system. However, different algorithms from interpolation, such as a simple winner-takes-all algorithm, induce a qualitatively similar result, as is shown in Figure 5. Thus, it can be concluded that the lower the units' preferred spatial frequency, the larger the illusion, and the higher the units' preferred spatial frequency, the smaller the illusion. Similar dependence of estimated orientation on the spatial frequency of the applied filters has been reported by Morgan and Casco (1990) in the case of the Zöllner illusion.

Figure 6 shows two images of the café wall figure with band-pass filtering whose center spatial frequency was 1.0 or $4.0 \mathrm{c} / \mathrm{deg}$, with a one-octave bandwidth. It can be seen that the image filtered by low spatial frequency induces a stronger impression of mortar line orientation than that filtered by high spatial frequency. This implies that the effect of spatial frequency on the strength of the illusion in Figure 5 reflects the fact that the local tilt in a mortar line (the so-called Fraser's twisted cord) is greater at a low spatial frequency.

The energy model with four spatial filters having a quadrature relationship has been used to simulate a function of a complex cell in V1 (e.g., DeAngelis \& Anzai,
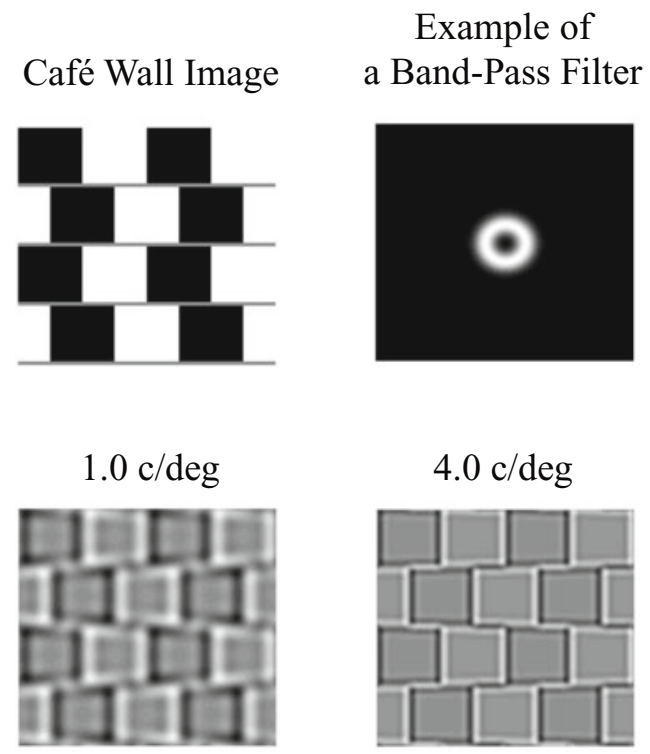

Figure 6. The café wall images after band-pass filtering. The center spatial frequency was 1.0 or $4.0 \mathrm{c} / \mathrm{deg}$, with a one-octave bandwidth. 
2004; Heeger, 1992). Recent studies, however, have shown that the phase difference between adjacent simple cells is not strictly gathered around $90^{\circ}$ or $180^{\circ}$ (DeAngelis, Ghose, Ohzawa, \& Freeman, 1999). A psychophysical study showed that the sensitivity to an odd-symmetric grating pattern decreased at the periphery faster than did that to an even-symmetric grating pattern (Bennett \& Banks, 1987). This suggests that each element of the quadrature pair could be a different mechanism. In addition, Peli (2002) demonstrated that an in-phase (sinusoidal) Gabor filter is sufficient for detecting both bar and edge features in natural images. Those studies cast doubt on the biological plausibility of the idea of a strict quadrature relationship between adjacent simple cells in V1.

Thus, to clarify a role of the phase of the Gabor filters, the possibility that an energy model with a single filter having a fixed phase would induce a prediction regarding the perceived orientation of a mortar line similar to that shown in Figure 5B was examined. The phase of the Gabor filter was even-symmetric $(\varphi=0$ in Equation 1) or odd-symmetric $(\varphi=\pi / 2$ in Equation 1). Two mortar luminances (average and black were examined). Figure 7 shows the estimated orientation of mortar lines as a function of normalized mortar luminance. The data from the quadrature filter condition in Figure 7 is replotted from Figure 5B. The results show that there are no significant differences between the three filter conditions, which suggest that a quadrature pair is not necessary for the estimation of orientation of mortar lines of the café wall figure.

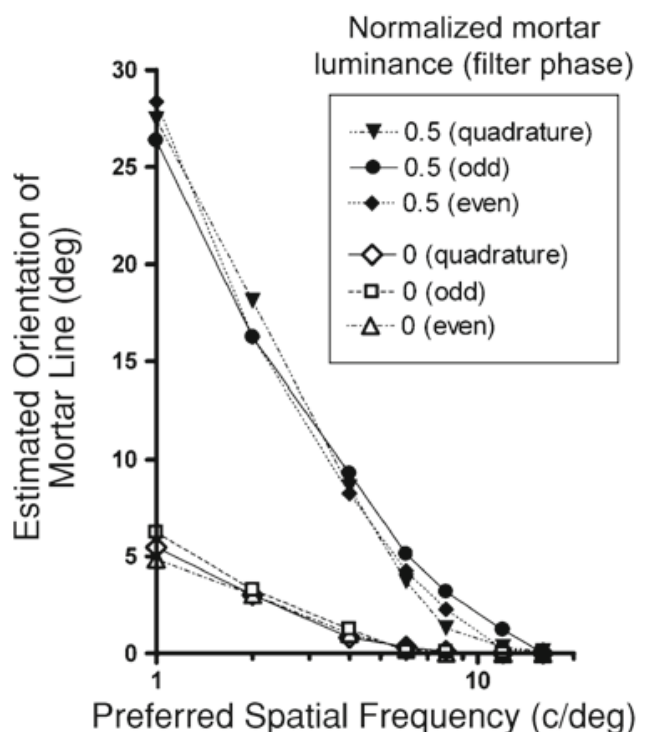

Figure 7. The estimated orientation of mortar lines (in degrees) is plotted as a function of preferred spatial frequency of an orientation-encoding unit (c/deg). Different symbols indicate a normalized mortar luminance $(0$ or 0.5$)$ and the phase of the Gabor filters (quadrature, odd symmetric, or even symmetric).
Since one's perceived orientation of the mortar line is unique, the various outputs from orientation-encoding units tuned to different spatial frequencies in Figure 5 must be integrated to induce a unique solution. In Figure 5 , the maximum expected strength of the café wall illusion is larger than $20^{\circ}$ when the mortar luminance is the average of that of the dark and light tiles. However, previous studies in which the perceived orientation of the mortar lines in café wall figures has been measured did not show such a large degree of orientation (e.g., Gregory \& Heard, 1979; the present psychophysical measurement, described below, showed about $3^{\circ}$ ). Since the estimated orientation is greater when the orientation-encoding units' preferred spatial frequency is lower (Figure 5B), signals from the orientation-encoding units tuned to lower spatial frequencies should be weakened, reducing the estimated mortar line orientation to a degree that matches our perception by some form of (weighted) averaging of responses from orientation-encoding units tuned to different spatial frequencies or by an inhibitory process from orientation-encoding units tuned to higher spatial frequencies with respect to those tuned to lower spatial frequencies. An interesting prediction can be made from this speculation: The strength of café wall illusion could increase when the signal from the orientation-encoding units tuned to higher spatial frequencies weakens.

Contrast sensitivity as a function of spatial frequency shows a band-pass shape at the fovea, in which the sensitivity to middle spatial frequency is the highest. However, when a pattern is displayed at the periphery, it is well known that visual sensitivity to higher spatial frequencies decreases (Barten, 1999; Kelly, 1984; Robson \& Graham, 1981; Rovamo, Virsu, \& Näsänen, 1978). As a result, peak sensitivity shifts to a lower spatial frequency, and the cutoff spatial frequency decreases.

Visual sensitivity also differs under different adaptation levels (the average luminance level of the display an observer is viewing), from photopic to mesopic to scotopic levels. A contrast sensitivity function is band-pass at photopic levels. As the average luminance level decreases, the peak sensitivity shifts to a lower spatial frequency, and the cutoff spatial frequency decreases (R. L. De Valois \& K. K. De Valois, 1988; R. L. De Valois, Morgan, \& Snodderly, 1974; Savage \& Banks, 1992; van Nes, Koenderink, Nas, \& Bouman, 1967).

Thus, it is predicted that the strength of the café wall illusion could increase under peripheral viewing or under low luminance levels if the strength of the illusion is determined by an integration of signals from orientationencoding units tuned to various spatial frequencies. To confirm this prediction, a series of psychophysical experiments was conducted to examine the effect of eccentricity and average luminance on the strength of the illusion, which, as far as is known, has not been examined before.

In addition, to examine the relationship between the strength of the café wall illusion and the spatial contrast 
sensitivity, the detection threshold contrast of a Gabor pattern having various spatial frequencies was also measured.

\section{EXPERIMENT}

\section{Method}

Subjects. The author and four naive subjects participated in the orientation judgment experiments of a mortar line of the café wall figure. The author and the same 3 naive subjects, except 1, participated in the detection experiment of a Gabor pattern. The subjects other than the author were unaware of the purpose and ongoing results of the experiment. All of them had normal or corrected-tonormal vision.

Apparatus. The stimuli were generated on a PC with a VSG 2/4 (Cambridge Research Systems) and were displayed on 21-in. RGB flat monitors (Sony GDM-F520; two monitors set side by side were used to display the stimulus at the periphery). The spatial resolution of the monitor was $1,024 \times 768$ pixels, and the number of intensity levels available for each pixel was set to 15 bits. The monitor was calibrated with a Topcon BM-5A luminance colorimeter, and its output was linearized (gamma corrected) under software control. The subjects observed the display monocularly from a distance of $57 \mathrm{~cm}$, with head position maintained by chin- and headrests. In the experiment in which the average luminance level was varied, the subjects observed the display through a $2-\mathrm{mm}$ artificial pupil. The room was darkened and light shielded, with no other source of illumination.

Stimuli. The café wall image $\left(4^{\circ} \times 4^{\circ}\right)$ consisted of four rows of tiles and five mortar lines. One row contained six tiles. The mortar width was $1.0 \mathrm{~min}$, which induces a strong illusion (Earle \& Maskell, 1993; Gregory \& Heard, 1979; Lulich \& Stevens, 1989). Examples of the café wall image used in the experiment are shown in Figures 2-4.

In the first experiment, the perceived orientation of the mortar lines was measured while the mortar luminance of the café wall image and the retinal eccentricity where the café wall image was displayed were systematically varied. The luminance was $36.0 \mathrm{~cd} / \mathrm{m}^{2}$ for the light tiles and $4.0 \mathrm{~cd} / \mathrm{m}^{2}$ for the dark ones (the Michelson contrast of tiles was $80 \%$ ). The luminance of the mortar lines was varied from 0.0 to $20.0 \mathrm{~cd} / \mathrm{m}^{2}$ in six steps. The luminance of $20.0 \mathrm{~cd} / \mathrm{m}^{2}$ corresponded to the average of the luminances of the light and the dark tiles (normalized luminance was 0.5 ). The café wall image was displayed at three eccentricities: $0.0^{\circ}, 4.5^{\circ}$, or $9.0^{\circ}$. The eccentricity was defined as the distance between the fixation point and the center of the café wall image. To keep the stimulus from falling in the blind spot, the café wall image was displayed on the temporal meridian with the right eye.

In the second experiment, the effect of the mean luminance on the café wall illusion was examined. The café wall images were the same as those in the first experiment, except that they were always displayed at the center of the display. The mean luminance level of the display was varied by placing neutral density filters just distal to the artificial pupil. The adapting levels varied from 1.8 to $-1.2 \mathrm{log}$ photopic trolands $(\log \mathrm{Tp})$ in four steps, which covers photopic to mesopic levels. The corresponding mean luminance values were 20.0, 2.0, 0.2, and $0.02 \mathrm{~cd} / \mathrm{m}^{2}$. Although the lowest luminance used, $-1.2 \log \mathrm{Tp}$, may be in the scotopic range (Hood \& Finkelstein, 1986; Stabell \& Stabell, 1981), some cones could be active at this luminance level, since the cone threshold depends not only on the stimulus parameters, but also on individual variations. Experimental sessions with different average luminance levels were run separately. The subjects adapted to the dark for $30 \mathrm{~min}$ before the beginning of the experimental sessions.

In the detection experiment, a Gabor pattern (Equation 1), a horizontal cosine-wave grating windowed by two-dimensional Gaussian functions in space ( $B=1.2$ in Equation 2$)$ and time ( $\left.\sigma_{t}=300 \mathrm{msec}\right)$, was displayed in a $4.0^{\circ} \times 4.0^{\circ}$ square window. Stimulus spatial frequencies varied from 0.5 to $16.0 \mathrm{c} / \mathrm{deg}$. Other conditions, such as average luminance or presentation duration, were similar to those in the other two orientation judgment experiments.

Procedure. A two-alternative temporal forced choice procedure was used to estimate the perceived mortar line orientation. In the first interval, the café wall image (standard stimulus) was displayed; in the second interval, a white straight line $4.0^{\circ}$ in length (comparison stimulus) was displayed on the gray background (the luminance was $20 \mathrm{~cd} / \mathrm{m}^{2}$ when the ND filter was not used). The line was anti-aliased to remove the jaggedness inherent in computer graphics displays (Tanner, Jolicœur, Cowan, Booth, \& Fishman, 1989). Each interval was presented for $2.0 \mathrm{sec}$, and the two intervals were separated by a 0.5 -sec gray blank field. The onset of each interval was marked by an auditory cue. A small fixation cross $\left(1^{\circ} \times 1^{\circ}\right)$ was presented at the center of the display for $500 \mathrm{msec}$ before the onset of each interval, and the subjects were instructed to fixate on the center of the display during each trial. The comparison stimulus (anti-aliased line) was always presented at the center of the display, regardless of whether the standard stimulus (café wall image) was displayed at the fovea or the periphery. When the café wall image was presented at the periphery, a small cross was always presented at the center of the display to maintain the subjects' fixation.

The subjects' task was to judge the orientation of the second mortar line of the café wall image. An adaptive staircase algorithm was used to measure the point of subjective equality (PSE) of the orientation of the standard stimulus (café wall figure) and the comparison stimulus (anti-aliased line) by changing the physical orientation of the comparison stimulus from trial to trial. When the comparison stimulus was judged to be more oriented than the standard stimulus, a decrement (to horizontal) in the orientation of the comparison stimulus followed; when the comparison stimulus was judged larger in orientation than the standard stimulus, its orientation was then increased. The size of the orientation increments or decrements decreased as the staircase depth increased, being $0.4 \log$ unit in the beginning and falling to a terminal value of $0.1 \log$ unit. The PSE for a given staircase run was computed as the mean of the orientations of the final 6 out of 20 turning points. This provided an estimate of the perceived orientation of the mortar line in the café wall image. Each data point was calculated from eight staircase runs.

To prevent adaptation to a specific configuration, two staircases, in which two types of positional relationship between the light and the dark tiles (whether the light tile was on the left or the right of the dark tile) were interleaved in a single session. In the first experiment, different experimental blocks were run for each eccentricity, and in the second experiment, different experimental blocks were run for each average luminance level.

In the Gabor pattern detection task, a two-alternative temporal forced choice procedure was used. In one of two intervals, the Gabor pattern appeared for $2.0 \mathrm{sec}$; in the other interval, only the blank field was displayed. The two intervals were separated by a 0.5 -sec blank field, and the onset of each interval was marked by an auditory cue. The subject, by pressing one of two buttons, indicated which interval contained the Gabor pattern. No feedback was given. The Michelson contrast of the Gabor pattern was varied using a staircase algorithm designed to converge to a $79 \%$ correct level (Levitt, 1971). Contrast was decreased after three consecutive correct responses and was increased after one wrong response. The size of the contrast increments or decrements decreased as the staircase depth increased, being $0.4 \log$ unit in the beginning and falling to a terminal value of $0.1 \log$ unit. The threshold for a given staircase run was computed as the mean of the contrasts of the final six out of nine turning points. Five staircases were run to determine each threshold. To prevent adaptation to a specific configuration, two staircases, in which two types of spatial frequencies were used, were interleaved 


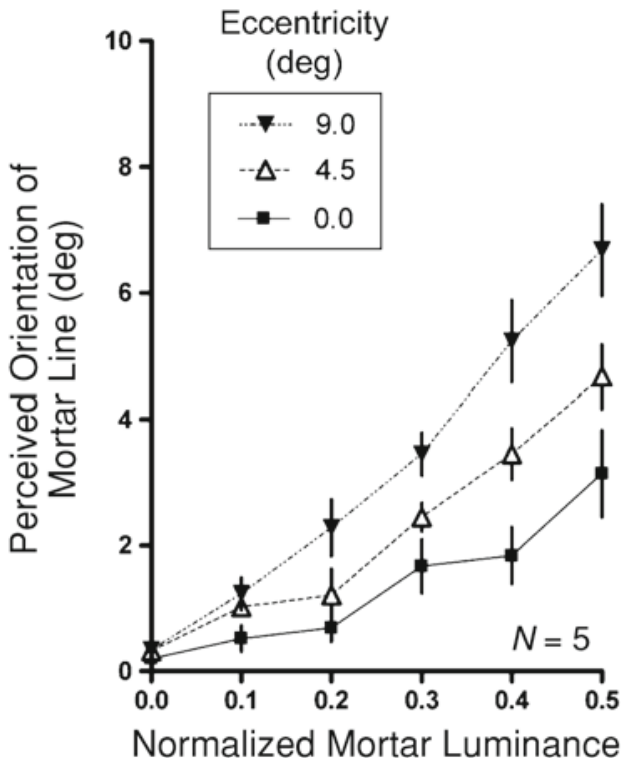

Figure 8. Perceived orientation of a mortar line is plotted as a function of normalized mortar luminance (averaged data of 5 subjects). Different symbols indicate the retinal location where the café wall image was displayed (from $0.0^{\circ}$ to $9.0^{\circ}$ in three steps). Error bars represent \pm 1 SEM.

in a single session. Similar measurements were made for each subject at each eccentricity and adapting level in different sessions.

\section{Results}

Figure 8 shows the results of the first experiment, in which the effect of eccentricity was examined. The perceived orientation of the mortar lines is plotted as a function of normalized mortar luminance. Three eccentricity conditions $\left(0.0^{\circ}, 4.5^{\circ}\right.$, and $\left.9.0^{\circ}\right)$ were examined. The perceived orientation increased as the mortar luminance increased, and the strength of the illusion reached $3.0^{\circ}$ at the fovea when the mortar luminance was the average of that of the light and the dark tiles (the normalized mortar luminance is 0.5 ). The illusion disappeared completely when the color of the mortar line was black (the normalized mortar luminance was 0.0 ). The strength of the illusion under foveal viewing is comparable to that measured previously by Gregory and Heard (1979) at high contrast (94\%) between light and dark tiles. Although a mortar luminance larger than the average luminance of the tiles was not examined, a previous study has shown that the strength of the illusion is maximum at the average luminance and decreases as the mortar luminance increases (Gregory \& Heard, 1979). A preliminary observation confirmed their conclusion.

Figure 8 also shows the results when the café wall image was displayed at the periphery. As the distance between the image and the fixation point increased from $4.5^{\circ}$ to $9.0^{\circ}$, the strength of the illusion increased more rapidly, when the mortar luminance increased, than when the café wall image was presented at the fovea. When the mortar luminance was the average of that of the light and the dark tiles (0.5), the perceived orientation of the mortar lines reached $4.6^{\circ}$ when the café wall image was displayed at $4.5^{\circ}$ eccentricity, and it reached $7.2^{\circ}$ when the image was presented at $9.0^{\circ}$ eccentricity. When the mortar luminance was darker than the average (0.5), the strength of the illusion was also larger when the image was displayed at periphery.

Figure 9 shows the perceived orientation of the mortar line as a function of normalized mortar luminance for four different average luminance conditions. The café wall image was displayed at the fovea. When the average luminance was $1.8 \log \mathrm{Tp}$ (photopic level; the average luminance of the background was $20 \mathrm{~cd} / \mathrm{m}^{2}$ ), the result was comparable to the data obtained under the foveal presentation condition in Figure 8. However, as the average luminance decreased from $1.8 \log \mathrm{Tp}$ to $-1.2 \log \mathrm{Tp}$ (mesopic level), the perceived orientation of the mortar line increased rapidly. When the average luminance was $-1.2 \log \mathrm{Tp}$, the perceived orientation of the mortar line was about $5.1^{\circ}$ at the mortar luminance of 0.5 , which is larger than the illusion obtained at the photopic conditions (1.8 $\log \mathrm{Tp}$ in Figure 9 or the foveal presentation condition in Figure 8). When the mortar luminance was darker than the average $(0.5)$, the strength of illusion was also larger when the image was observed at low luminance levels.

In summary, it was found that the café wall illusion is stronger at the periphery (at least, up to $9.0^{\circ}$ ) or under low average luminance levels (at least, down to the mesopic level).

Figure 10 shows the contrast sensitivity (a reciprocal of luminance contrast at detection threshold) to a Gabor

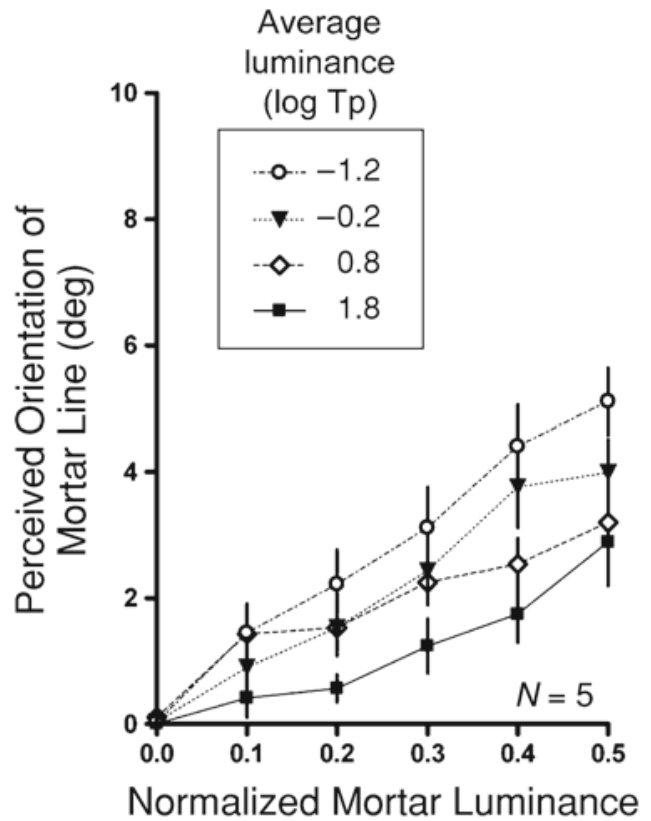

Figure 9. Perceived orientation of a mortar line is plotted as a function of normalized mortar luminance (averaged data of 5 subjects). Different symbols indicate the average luminance level (from 1.8 to $-1.2 \log \mathrm{Tp}$ in four steps). Error bars represent $\pm 1 S E M$. 
(A)

(C)

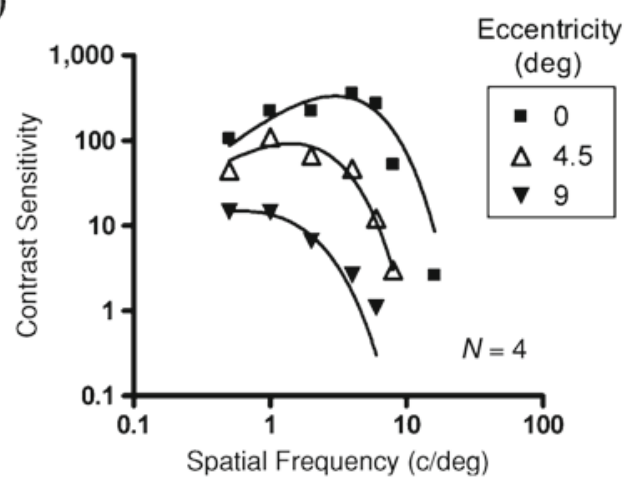

(B)

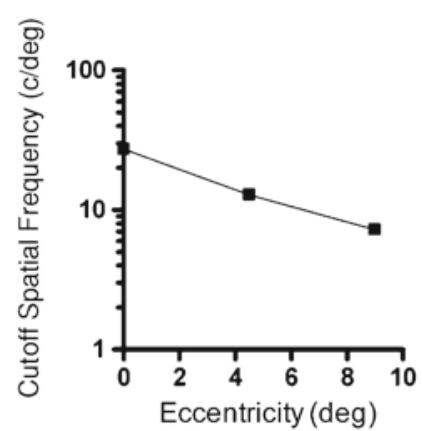

(D)

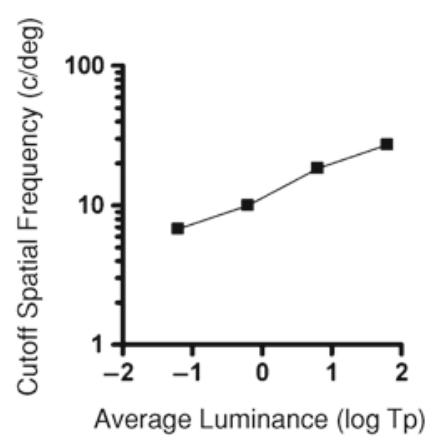

Figure 10. (A) Contrast sensitivity for detection of a Gabor pattern is plotted as a function of the spatial frequency (c/deg). Eccentricity varied from $0.0^{\circ}$ (fovea) to $9.0^{\circ}$. (B) Cutoff spatial frequency (c/deg) estimated from the contrast sensitivity data (panel $A$ ) is plotted as a function of eccentricity (deg). (C) Contrast sensitivity for detection of a Gabor pattern is plotted as a function of the spatial frequency (c/deg). Average luminance levels varied from 1.8 to $-1.2 \log$ photopic Td $(\log \mathrm{Tp})$. (D) Cutoff spatial frequency (c/deg) estimated from the contrast sensitivity data (panel $\mathrm{C}$ ) is plotted as a function of average luminance (log $\mathrm{Tp}$ ).

pattern observed at different eccentricities (A) or under different adapting levels (C) as a function of spatial frequency. The well-known characteristics that the peak sensitivity and the cutoff spatial frequency shift to lower spatial frequencies as the eccentricity increases or the adapting level decreases (e.g., Barten, 1999) were confirmed. To estimate the cutoff spatial frequency at each viewing condition from the data, the function proposed by Wilson and Giese (1977) was fitted (the smooth curves in Figures $10 \mathrm{~A}$ and $10 \mathrm{C}){ }^{2}$ The estimated cutoff spatial frequencies from Figure 10A are shown in Figure 10B. Figure 10D shows the estimated cutoff spatial frequencies from Figure 10C. The cutoff spatial frequency decreased as the eccentricity increased or the adapting level decreased. In the following discussion, the estimated cutoff spatial frequencies will be used to quantitatively predict the strength of the café wall illusion (Figure 11).

\section{Discussion}

As was described in the previous section, since one's perceived orientation of the mortar line is unique, the responses from orientation-encoding units tuned to different spatial frequencies should be combined to induce a unique solution. How the information obtained from multiscale spatial filtering is combined is a challenging problem, and to date, many different algorithms have been proposed (e.g., Freeman \& Adelson, 1991; Georgeson \& Meese, 1997; Marr, 1982; Marr \& Hildreth, 1980; Morrone \& Burr, 1988; Peli, 2002; Watt, 1990; Watt \& Morgan, 1985).

In this section, an attempt has been made to examine whether a simple computation, such as a weighted averaging, can quantitatively predict the psychophysically measured perceived mortar line orientation shown in Figures 8 and 9 . We found that a simple weighted averaging overestimates the strength of the café wall illusion. The estimated mortar orientation across the spatial frequencies shown in Figure 5A were averaged to induce a single estimation of mortar orientation at each mortar luminance. Since the estimated mortar orientation was nearly zero when the preferred spatial frequency was higher than $16 \mathrm{c} / \mathrm{deg}$ (Figure 5), the estimated mortar orientation obtained from the orientation-encoding units tuned to spatial frequencies higher than $16 \mathrm{c} / \mathrm{deg}$ was not included in the averaging.

Weighting across spatial frequency is a power function with a slope of 0.1 , which was proposed by Blakeslee and McCourt (2004) on the basis of the suprathreshold con- 
(A)

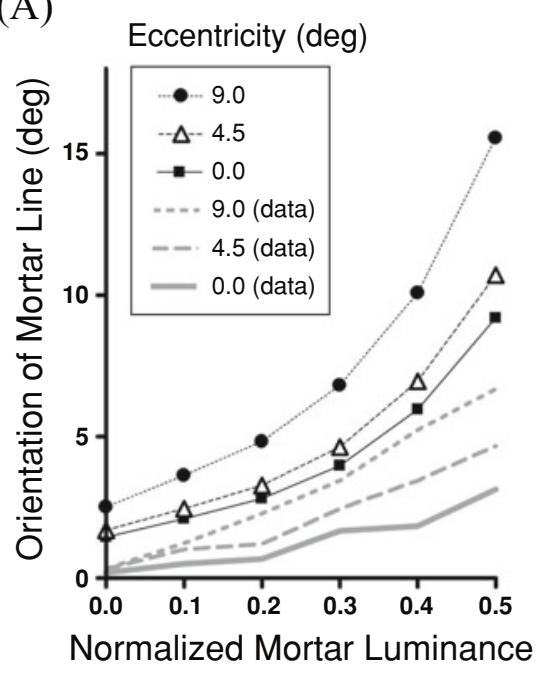

(B) Average luminance $(\log T p)$

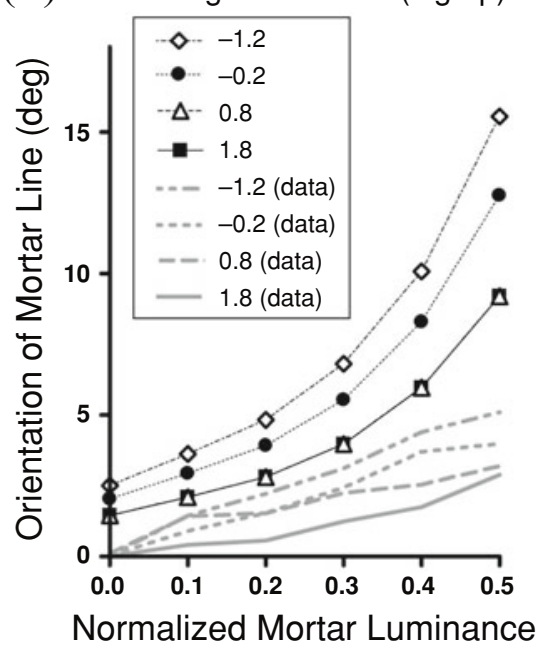

Figure 11. (A) Predicted and measured orientations of the mortar line (in degrees) are plotted as functions of normalized mortar luminance. Gray lines represent the psychophysically measured mortar orientations, replotted from Figure 8. Different symbols indicate the predicted mortar orientations for each eccentricity. (B) Predicted and measured orientations of the mortar line (in degrees) are plotted as functions of normalized mortar luminance. Gray lines represent the psychophysically measured mortar orientations, replotted from Figure 9. Different symbols indicate the predicted mortar orientations for each average luminance.

trast sensitivity measurement of Georgeson and Sullivan (1975). This function was chosen because the café wall illusion is a suprathreshold phenomenon.

In addition, the mortar orientations in Figure 5A, obtained at a spatial frequency greater than the cutoff spatial frequencies estimated at each viewing condition (Figures 10B and 10D), are omitted from the averaging, since such high spatial frequency information is not supposed to be available to the visual system. For example, to predict the perceived mortar line orientation when the average luminance is $-1.2 \log \mathrm{Tp}$, mortar orientations obtained at the preferred spatial frequency smaller than $6 \mathrm{c} / \mathrm{deg}$ are averaged, since the contrast measurement shows that patterns having a spatial frequency larger than $6 \mathrm{c} / \mathrm{deg}$ are not expected to be detected (Figure 10D).

Figure 11 shows the results of the weighted averaging of mortar orientation at each eccentricity (A) or each average luminance (B), in addition to a replot of the psychophysical measurements shown in Figures 8 and 9 (gray lines in Figure 11). Since the cutoff spatial frequency is larger than $16 \mathrm{c} / \mathrm{deg}$ at the average luminances of 1.8 and $0.8 \log$ Tp (Figure 10D), the calculated mortar orientations are the same for those two conditions (Figure 11B). The results of the weighted averaging qualitatively capture the effects of eccentricity and average luminance on the perception of the café wall illusion. However, the results also clearly show that the weighted average overestimates the perceived mortar line orientation at every mortar luminance. Thus, the procedure above is not enough to quantitatively predict the mortar line orientation.

To resolve this problem, averaging with more complicated weighting functions might be needed. For example, a weighting function that enhances signals from orientationencoding units tuned to higher spatial frequencies may reduce the estimated orientation of the mortar lines to a degree that matches perception, since the estimated orientation from the orientation-encoding units tuned to lower spatial frequencies are far greater than the psychophysically measured orientation. This matter will be discussed in the next section.

\section{GENERAL DISCUSSION}

\section{Summary of Results}

In this study, the currently prevailing energy-based orientation-encoding model was implemented to estimate the strength of the café wall illusion. It was found that the estimated orientation of mortar lines of the café wall image depends not only on the mortar luminance, but also on the preferred spatial frequency of orientation-encoding units. When the preferred spatial frequency is lower, the estimated orientation is greater at any mortar luminance. This leads to the prediction that the strength of the café wall illusion increases when the signals from orientationencoding units tuned to higher spatial frequencies are weakened. In subsequent psychophysical experiments, the eccentricity and the average luminance levels were systematically varied and the effects of these two viewing conditions on the perception of the café wall illusion were measured. In agreement with what we predicted, the illusion was stronger when the café wall image was presented at the periphery or was observed under mesopic vision than when it was observed at the fovea or under photopic vision. 


\section{Possible Mechanism}

The maximum perceived orientation of mortar lines in the café wall image at the fovea under photopic vision is around $3.0^{\circ}$ (Figures 8 and 9), whereas the maximum predicted orientation varied from about $0^{\circ}$ to $30^{\circ}$, depending on the preferred spatial frequency of the orientationencoding units, at a mortar luminance of 0.5 (Figure 5). Thus, if we assume that the results of the present simulation (Figure 5) represent the strength of the café wall illusion at the fovea under photopic vision (a typical observation condition), there should be an integration of signals from orientation-encoding units tuned to different spatial frequencies. As is shown in Figure 11, averaging with a specific weighting across spatial frequencies overestimates the strength of the café wall illusion. This suggests that other types of weighting functions are needed in order to quantitatively predict the café wall illusion. As was described above, one candidate is a weighting function that enhances signals from orientation-encoding units tuned to higher spatial frequencies. This kind of weighting function could be induced by assuming a nonlinear interaction, such as an inhibition from orientation-encoding units tuned to higher spatial frequency to ones tuned to lower spatial frequency. In fact, there is considerable psychophysical and physiological evidence showing that there are significant inhibitory interactions among channels tuned to different spatial frequencies (e.g., Bauman \& Bonds, 1991; K. K. De Valois, 1977; K. K. De Valois \& Tootell, 1983; Heeger, 1992; Nachmias, Sansbury, Vassilev, \& Weber, 1973; Nestares \& Heeger, 1997; Tolhurst, 1972). For example, K. K. De Valois and Tootell found that the response of simple cells in the cat striate cortex is inhibited by the addition of a high spatial frequency component. Functionally, an interaction can be formalized by way of normalization at the integration stage. Further research is needed to clarify which model is more appropriate.

\section{Integration of Local Energy}

Although mortar lines in the café wall figure are perceived to be globally tilted, each orientation-encoding unit (Figure 2) used in present model is spatially localized. This points to the existence of some mechanisms that integrate the outputs from spatially local operators to induce a global percept. In the present model, the perceived orientation of the mortar lines was estimated by summing the orientation energy distributed at the positions of the mortar line in the output image (Figure 4). This kind of operation can be formalized as an integrator mechanism. For example, Morgan and Hotopf (1989) proposed "log-line detectors" that collect inputs from spatially localized orientation-selective detectors to account for the perceived tilt of Fraser's twisted cord (see also Tyler \& Nakayama, 1984). Instead of assuming an integrating mechanism, Stuart and Bossomaier (1992) suggested that synchrony in the firing rate of cells (e.g., Gray, König, Engel, \& Singer, 1989) is the key feature of integration for the global perception of orientation. Clarifying how the global percept of orientation is accomplished is a challenge for future research.

\section{Reversed Café Wall Illusion}

When the mortar is wide (above $10 \mathrm{~min}$ arc or so), the so-called reversed café wall illusion, in which the perceived tilt of the mortar line is opposite to that of the standard café wall illusion, is perceived (Earle \& Maskell, 1993; Lulich \& Stevens, 1989). It has been shown that reversed Fraser's twisted cords appear after band-pass filtering with a preferred spatial frequency of around 3-7 c/deg (Earle \& Maskell, 1993). Therefore, although a simulation was not conducted in the present study, it is expected that if an input image with a wide mortar line were used, the café wall illusion would be reversed.

\section{Spatiotemporal Café Wall Illusion}

Takeuchi (1997) found that the café wall pattern induces an illusion of motion when the pattern is converted from the space-space $(x-y)$ domain to the space-time $(x-t)$ domain. The stationary mortar lines are perceived to move and even induce a motion aftereffect. The strength of the motion illusion depends on the mortar luminance, as in the standard café wall illusion. The motion energy model (Adelson \& Bergen, 1985) predicted the strength of this motion illusion. Since the present study showed that the orientation energy model can predict the induction of the café wall illusion, detecting spatiotemporally oriented contours (motion) and spatially oriented contours (orientation) can be considered a computationally equivalent operation (Adelson \& Bergen, 1991; Gorea \& Papathomas, 1991).

\section{REFERENCES}

Adelson, E. H., \& Bergen, J. R. (1985). Spatiotemporal energy models for the perception of motion. Journal of the Optical Society of America A, 2, 284-299.

Adelson, E. H., \& Bergen, J. R. (1991). The plenoptic function and the elements of early vision. In M. S. Landy \& J. A. Movshon (Eds.), Computational models of visual processing (pp. 3-20). Cambridge, MA: MIT Press.

Anzai, A., Ohzawa, I., \& Freeman, R. D. (1999). Neural mechanisms for processing binocular information: II. Complex cells. Journal of Neurophysiology, 82, 909-924.

BARTEN, P. G. J. (1999). Contrast sensitivity of the human eye and its effects on image quality. Bellingham, WA: SPIE Optical Engineering Press.

Bauman, L. A., \& Bonds, A. B. (1991). Inhibitory refinement of spatial frequency selectivity in single cells of the cat striate cortex. Vision Research, 31, 933-944.

Bennett, P. J., \& BAnKs, M. S. (1987). Sensitivity loss in odd-symmetric mechanisms and phase anomalies in peripheral vision. Nature, 326, 873-876.

Bergen, J. R., \& Landy, M. S. (1991). Computational modeling of visual texture segregation. In M. S. Landy \& J. A. Movshon (Eds.), Computational models of visual processing (pp. 253-271). Cambridge, MA: MIT Press.

Blakemore, C., \& Campbell, F. W. (1969). On the existence of neurones in the human visual system selectively sensitive to the orientation and size of retinal images. Journal of Physiology, 203, 237-260.

Blakeslee, B., \& McCourt, M. E. (2004). A unified theory of brightness contrast and assimilation incorporating oriented multiscale spa- 
tial filtering and contrast normalization. Vision Research, 44, 24832503.

Campbell, F. W., \& Kulikowski, J. J. (1966). Orientation selectivity of the human visual system. Journal of Physiology, 187, 437-445.

Carandini, M., Heeger, D. J., \& Movshon, J. A. (1999). Linearity and gain control in V1 simple cells. In E. G. Jones \& P. S. Ulinski (Eds.), Cerebral cortex: Vol. XII. Cortical model (pp. 401-443). New York: Plenum

Daugman, J. G. (1985). Uncertainty relation for resolution in space, spatial frequency, and orientation optimized by two-dimensional visual cortical filters. Journal of the Optical Society of America A, 2, 1160-1169.

DeAngelis, G. C., \& AnZAI, A. (2004). A modern view of the classical receptive field: Linear and nonlinear spatiotemporal processing by $\mathrm{V} 1$ neurons. In L. M. Chalupa \& J. S. Werner (Eds.), The visual neurosciences (pp. 704-719). Cambridge, MA: MIT Press

DeAngelis, G. C., Ghose, G. M., Ohzawa, I., \& Freeman, R. D. (1999). Functional micro-organization of primary visual cortex: Receptive field analysis of nearby neurons. Journal of Neuroscience, 19, 4046-4064.

De VALOIS, K. K. (1977). Spatial frequency adaptation can enhance contrast sensitivity. Vision Research, 17, 1057-1065.

De Valois, K. K., \& ToOTell, R. B. H. (1983). Spatial-frequency-specific inhibition in cat striate cortex cells. Journal of Physiology, 291, 483505.

De Valois, R. L., Albrecht, D. G., \& Thorell, L. G. (1982). Spatial frequency selectivity of cells in macaque visual cortex. Vision Research, 22, 545-559.

De Valois, R. L., \& De Valois, K. K. (1988). Spatial vision. New York: Oxford University Press

De Valois, R. L., Morgan, H., \& Snodderly, D. M. (1974). Psychophysical studies of monkey vision: 3 . Spatial luminance contrast sensitivity tests of macaque and human observers. Vision Research, 14 $75-81$

EARLE, D. C., \& MASKell, S. J. (1993). Fraser cords and reversal of the café wall illusion. Perception, 22, 383-390.

EMERSON, R. C., Bergen, J. R., \& Adelson, E. H. (1992). Directionally selective complex cells and the computation of motion energy in cat visual cortex. Vision Research, 32, 203-218.

Field, D. J., \& Tolhurst, D. J. (1986). The structure and symmetry of simple-cell receptive-field profiles in the cat's visual cortex. Proceedings of the Royal Society of London: Series B, 228, 379-400.

FrASER, J. (1908). A new illusion of visual direction. British Journal of Psychology, 2, 307-320.

Freeman, W. T., \& Adelson, E. H. (1991). The design and use of steerable filters. IEEE Transactions on Pattern Analysis \& Machine Intelligence, 13, 891-906.

Georgeson, M. A., \& Meese, T. S. (1997). Perception of stationary plaids: The role of spatial filters in edge analysis. Vision Research, 37, 3255-3271.

Georgeson, M. A., \& Sullivan, G. D. (1975). Contrast constancy: Deblurring in human vision by spatial frequency channels. Journal of Physiology, 252, 627-656.

Gorea, A., \& Papathomas, T. V. (1991). Texture segregation by chromatic and achromatic visual pathways: An analogy with motion processing. Journal of the Optical Society of America A, 8, 386-393.

Gray, C. M., KöNIG, P., Engel, A. K., \& Singer, W. (1989). Oscillatory responses in cat visual cortex exhibit inter-columnar synchronization which reflects global stimulus properties. Nature, 338, 334-337.

Gregory, R. L. (1968). Visual illusions. Scientific American, 219, 6676.

Gregory, R. L. (1972). [Editorial]. Perception, 1, 492.

Gregory, R. L., \& HEARD, P. F. (1979). Border locking and the café wall illusion. Perception, 8, 365-380

HaIG, N. D. (1989). A new visual illusion, and its mechanism. Perception, 18, 333-345.

HeEger, D. J. (1992). Normalization of cell responses in cat striate cortex. Visual Neuroscience, 9, 181-197.

Hood, D. C., \& Finkelstein, M. A. (1986). Visual sensitivity. In
K. R. Boff, L. Kaufman, \& J. P. Thomas (Eds.), Handbook of perception and human performance (Vol. 1, pp. 1-66). New York: Wiley.

HubEL, D. H., \& WiESEL, T. (1962). Receptive fields, binocular interaction, and functional architecture in the cat's visual cortex. Journal of Physiology, 160, 106-154.

KeLLY, D. H. (1984). Retinal inhomogeneity: I. Spatiotemporal contrast sensitivity. Journal of the Optical Society of America A, 1, 107-113.

Kruizinga, P., \& PetKov, N. (1999). Nonlinear operator for oriented texture. IEEE Transactions on Image Processing, 8, 1395-1407.

LEVITT, H. (1971). Transformed up-down methods in psychoacoustics. Journal of the Acoustical Society of America, 49, 467-477.

Lulich, D. P., \& Stevens, K. A. (1989). Differential contributions of circular and elongated spatial filters to the café wall illusion. Biological Cybernetics, 61, 427-435.

Malik, J., \& Perona, P. (1990). Preattentive texture discrimination with early vision mechanisms. Journal of the Optical Society of America $A, 7,923-932$

MARR, D. (1982). Vision: A Computational investigation into the human representation and processing of visual information. San Francisco: Freeman.

Marr, D., \& Hildreth, E. (1980). Theory of edge detection. Proceedings of the Royal Society of London: Series B, 207, 187-217.

Morgan, M. J., \& Casco, C. (1990). Spatial filtering and spatial primitives in early vision: An explanation of the Zöllner-Judd class of geometrical illusion. Proceedings of the Royal Society of London: Series $B, \mathbf{2 4 2}, 1-10$

Morgan, M. J., \& Hotopf, H. N. (1989). Perceived diagonals in grids and lattices. Vision Research, 29, 1005-1015.

Morgan, M. J., \& Moulden, B. (1986). The Münsterberg figure and twisted cords. Vision Research, 26, 1793-1800.

Morrone, M. C., \& Burr, D. C. (1988). Feature detection in human vision: A phase dependent energy model. Proceedings of the Royal Society of London: Series B, 235, 221-245.

MÜNSTERBERG, H. (1897). Die verschobene Schachbrettfigur. Zeitschrift für Psychologie, 5, 185-188.

Nachmias, J., Sansbury, R., Vassilev, A., \& Weber, A. (1973). Adaptation to square-wave gratings: In search of the elusive third harmonic. Vision Research, 13, 1335-1342.

Nestares, O., \& Heeger, D. J. (1997). Modeling the apparent frequencyspecific suppression in simple cell responses. Vision Research, 37, $1535-1543$

Ohzawa, I., DeAngelis, G. C., \& Freeman, R. D. (1990). Stereoscopic depth discrimination in the visual cortex: Neurons ideally suited as disparity detectors. Science, 249, 1037-1041.

PeLI, E. (2002). Feature detection algorithm based on a visual system model. Proceedings of the IEEE, 90, 78-93.

PetKov, N., \& Kruizinga, P. (1997). Computational models of visual neurons specialized in the detection of periodic and aperiodic oriented visual stimuli: Bar and grating cells. Biological Cybernetics, 76, 83-96.

Phillips, G. C., \& Wilson, H. R. (1984). Orientation bandwidths of spatial mechanisms measured by masking. Journal of the Optical Society of America A, 1, 226-232.

Pollen, D. A., \& RonNer, S. F. (1983). Visual cortical neurons as localized spatial frequency filters. IEEE Transactions on Systems, Man, \& Cybernetics, 13, 907-916.

Robson, J. G., \& Graham, N. (1981). Probability summation and regional variation in contrast sensitivity across the visual field. Vision Research, 21, 409-418.

Rock, I. (1986). The description and analysis of object and event perception. In K. R. Boff, L. Kaufman, \& J. P. Thomas (Eds.), Handbook of perception and human performance (Vol. 2, pp. 33-71). New York: Wiley

Rovamo, J., VIRsu, V., \& NÄsÄNEN, R. (1978). Cortical magnification factor predicts the photopic contrast sensitivity of peripheral vision. Nature, 271, 54-56.

SAVAGE, G. L., \& Banks, M. S. (1992). Scotopic visual efficiency: Constraints by optics, receptor properties and rod pooling. Vision Research, 32, 645-656. 
Stabell, B., \& Stabell, U. (1981). Absolute spectral sensitivity at different eccentricities. Journal of the Optical Society of America, 71, 836-840.

Stuart, G. W., \& Bossomaier, T. R. J. (1992). Cooperative representation of visual borders. Perception, 21, 185-194.

TAKeuchi, T. (1997). The motion analogue of the café wall illusion. Perception, 26, 569-584.

Tanner, P. P., Joliceur, P., Cowan, W. B., Booth, K., \& Fishman, F. D. (1989). Antialiasing: A technique for smoothing jagged lines on a computer graphics image - an implementation on the Amiga. Behavior Research Methods, Instruments, \& Computers, 21, 59-66.

TolHurst, D. J. (1972). Adaptation to square-wave gratings: Inhibition between spatial frequency channels in the human visual system. Journal of Physiology, 226, 231-248.

Tyler, C. W., \& NaKayama, K. (1984). Size interactions in the perception of orientation. In L. Spillman \& B. R. Woten (Eds.), Sensory experience and perception (pp. 529-546). Hillsdale, NJ: Erlbaum.

van Nes, F. L., Koenderink, J. J., Nas, H., \& Bouman, M. A. (1967). Spatiotemporal modulation transfer in the human eye. Journal of the Optical Society of America, 57, 1082-1088.

WATSON, A. B., \& Ahumada, A. (1985). Model of human visual motion sensing. Journal of the Optical Society of America A, 2, 322-341.

WATT, R. J. (1990). Visual processing: Computational, psychophysical and cognitive research. London: Psychology Press.

WATt, R. J., \& MoRgan, M. J. (1985). A theory of the primitive spatial code in human vision. Vision Research, 37, 127-142.
Wilson, H. R., Ferrera, V. P., \& Yo, C. (1992). A psychophysically motivated model for two-dimensional motion perception. Visual Neuroscience, 9, 79-97.

Wilson, H. R., \& Giese, S. (1977). Threshold visibility of frequency gradient patterns. Vision Research, 17, 1177-1190.

Wilson, H. R., McFarlane, D. K., \& Phillips, G. C. (1983). Spatial frequency tuning of orientation selective units estimated by oblique masking. Vision Research, 23, 873-882.

WiLSON, H. R., \& WILKINSON, F. (2004). Spatial channels in vision and spatial pooling. In L. M. Chalupa \& J. S. Werner (Eds.), The visual neurosciences (pp. 1060-1068). Cambridge, MA: MIT Press.

\section{NOTES}

1. Videos showing how orientation energy varies while orientation and spatial frequency of the Gabor filter change can be viewed at http:/ www.brl.ntt.co.jp/people/takeuchi/cafewall/cafewall.html.

2. The mathematical description of the contrast sensitivity function with three parameters, $M, f$, and $\alpha$, was adopted, following Wilson and Giese (1977, Equation 14) and Wilson and Wilkinson (2004, Equation 1). The function is as follows:

$$
\operatorname{CSF}(\omega)=M \omega^{\alpha} \exp (-\omega / f) .
$$

(Manuscript received March 10, 2003; revision accepted for publication December 13, 2004.) 